\title{
A Computational Study on the Use of an Aluminium Metal Matrix Composite and Aramid as Alternative Brake Disc and Brake Pad Material
}

\author{
Nosa Idusuyi, ${ }^{1}$ Ijeoma Babajide, ${ }^{1}$ Oluwaseun. K. Ajayi, ${ }^{2}$ and Temilola. T. Olugasa ${ }^{1}$ \\ ${ }^{1}$ Mechanical Engineering Department, University of Ibadan, Ibadan, Nigeria \\ ${ }^{2}$ Mechanical Engineering Department, Federal Polytechnic Ede, Osun State, Nigeria
}

Correspondence should be addressed to Nosa Idusuyi; nosaidus@gmail.com

Received 15 May 2014; Accepted 30 July 2014; Published 26 August 2014

Academic Editor: Sheng-Rui Jian

Copyright (C) 2014 Nosa Idusuyi et al. This is an open access article distributed under the Creative Commons Attribution License, which permits unrestricted use, distribution, and reproduction in any medium, provided the original work is properly cited.

\begin{abstract}
A computational model for the heat generation and dissipation in a disk brake during braking and the following release period has been formulated. The model simulates the braking action by investigating the thermal behaviour occurring on the disc and pad surfaces during this period. A comparative study was made between grey cast iron (GCI), asbestos, Aluminium metal matrix composite (AMC), and aramid as brake pad and disc materials. The braking process and following release period were simulated for four material combinations, GCI disc and Asbestos pad, GCI disc and Aramid pad, AMC disc and Asbestos pad, AMC disc and Aramid pad using COMSOL Multiphysics software. The results show similarity in thermal behaviour at the contact surface for the asbestos and aramid brake pad materials with a temperature difference of $1.8 \mathrm{~K}$ after 10 seconds. For the brake disc materials, the thermal behaviour was close, with the highest temperature difference being $9.6 \mathrm{~K}$. The GCI had a peak temperature of $489 \mathrm{~K}$ at 1.2 seconds and AMC was $465.5 \mathrm{~K}$ but cooling to $406.4 \mathrm{~K}$ at 10 seconds, while the GCI was $394.7 \mathrm{~K}$.
\end{abstract}

\section{Introduction}

Braking is an essential phenomenon in engineering applications with the automobiles industry as the chief user. More than 2000 different materials and their variants are currently used in commercial brake components [1]. Braking is a process that converts kinetic energy into mechanical energy and heat energy. The frictional heat generated at the disc-pad interface can lead to high temperatures in this component. In order to achieve a desired property for brake materials, composite materials are compounded to produce a better unit.

In a braking system, the mechanical energy is converted into a calorific energy characterized by a total heating of the disc and pads during the braking phase to temperatures between 300 and $800^{\circ} \mathrm{C}$ [2].

Finite element method is one of the best methods for analyzing heat conduction in disc brake system. Belhocine and Bouchetara [2] performed a study analyzing thermal behavior of the full and ventilated brake discs of vehicles using ANSYS; it was discovered that type of braking, geometry of disc, and material used affected the result. The governing heat equation for disc and the pad can be extracted in the form of heat equations with heat generation dependent on time and space [3].

Herbert Frood is credited with inventing the first brake lining materials in 1897. It was a cotton-based material impregnated with bitumen solution and was used for wagon wheels as well as early automobiles [1].

Belhocine and Bouchetara [2] performed a study to analyze the thermal behavior of the full and ventilated brake discs of the vehicles using computing code ANSYS it was seen that during the braking phase, the frictional heat generated at the interface of the disc and pads can lead to high temperatures. According to Talati and Jalalifar [3], the governing heat equations for the disc and the pad are extracted in the form of transient heat equations with heat generation that is dependent on time and space. In the derivation of the heat equations, parameters such as the duration of braking, vehicle velocity, geometries, and 
the dimensions of the brake components, materials of the disc brake rotor and the pad and contact pressure distribution were taken into account. Omolayo and Ogheneortega [4] modeled the heat generation and dissipation in a disc brake during braking and the following release period.

Österle et al. [5] focused on surface changes induced by repeated brake applications and tried to provide explanations for how such material modifications might affect friction and wear properties of automotive disc brakes. Satapathy and Bijwe [6] dealt with the wear data analysis of friction composites where the nature and the concentration of the abrasives were varied systematically in steps of $2 \%$. The abrasives selected were $\mathrm{SiC}, \mathrm{SiO}_{2}, \mathrm{ZrO}_{2}$, and $\mathrm{Al}_{2} \mathrm{O}_{3}$ in the concentration range of $2-6 \%$.

The long repetitive braking performance of aluminum metal matrix composite and nonasbestos organic friction material-aramid as brake disc and pad materials, respectively, were studied using COMSOL multiphysics 4.0 finite element software.

\section{Materials and Methods}

2.1. Theoretical Background. The heat transfer in a solid brake disc can be through all three modes of heat transfer. The friction heat generated in a brake disc is produced at the contact surface between the brake pad and disc and is transferred to other parts of the component by conduction; some of the heat is also dissipated to the surrounding through convection and radiation.

2.1.1. Governing Equations. The brakes retardation power is given by the negative of the time derivative of the car's kinetic energy (COMSOL multiphysics 4.0 software material library):

$$
P=-\frac{d}{d t}\left(\frac{m v^{2}}{2}\right)=-m v \frac{d v}{d t}=-m R^{2} \omega(t) \alpha,
$$

where $m$ is car mass $(\mathrm{kg}), v$ is car velocity $\left(\mathrm{m} / \mathrm{s}^{2}\right), R$ is wheel radius $(\mathrm{m}), \omega$ is angular velocity $(\mathrm{rad} / \mathrm{s}), \alpha$ is angular acceleration $\left(\mathrm{rad} / \mathrm{s}^{2}\right)$, and the acceleration is constant in this case so $\omega(t)=\omega_{0}+\alpha t$.

The friction force per unit area is approximately constant over the surface and is directed opposite the disc velocity:

$$
P=-8 \iint f_{f} d A \cdot v=8 f_{f}(t) \omega(t) \iint r d A,
$$

where

$$
v(r, t)=\omega(t) r
$$

$f_{f}=$ friction force per unit area $\left(\mathrm{N} / \mathrm{m}^{2}\right), d A=$ pad area $\left(\mathrm{m}^{2}\right)$, and $r=$ radius $(\mathrm{m})$.

Combining (1) and (2) we obtain

$$
f_{f}=-\frac{m R^{2} \alpha}{8 r_{m} A}
$$

The heat generated per unit contact area at time $t$ and distance $r$ from the center becomes

$$
\begin{gathered}
q(r, t)=-f_{f} \cdot v, \\
q(r, t)=\frac{m R^{2} \alpha}{8 r_{m} A} \cdot r\left(\omega_{0}+\alpha t\right) .
\end{gathered}
$$

This heat produced at the boundary between the brake disc and pad is dissipated by convection and radiation:

$$
\rho C_{p} \frac{\partial T}{\partial t}+\nabla \cdot(-k \nabla T)=Q-\rho C_{p} u \cdot \nabla T,
$$

$Q=$ heating power per unit volume $\left(\mathrm{W} / \mathrm{m}^{3}\right)$, which in this case is zero.

Since the heat dissipated from the disc and pad surfaces to the surrounding air is described by both convection and radiation, the expression becomes

$$
q_{\text {diss }}=-h\left(T-T_{\text {ref }}\right)-\varepsilon \sigma\left(T^{4}-T_{\text {ref }}^{4}\right) .
$$

To calculate the convective film coefficient as a function of the vehicle velocity $v$, we use the following formula:

$$
h=\frac{0.037 k}{l} \operatorname{Re}^{0.8} \operatorname{Pr}^{0.33}=\frac{0.037 k}{l}\left(\frac{\rho l v}{\mu}\right)^{0.8}\left(\frac{C_{p} \mu}{k}\right)^{0.33} \text {. }
$$

2.2. Brake Pad and Disc Material Properties. The potential AMC candidate material selected for the automotive brake disc is a $20 \% \mathrm{SiC}$ (Silicon Carbide) reinforced aluminiumcomposite.

2.3. Model Definition. This study models the heat generation and dissipation in a disc brake of an ordinary car during panic braking and the following release period. The typical car weighs $1800 \mathrm{~kg}$. In this model it initially travels at $25 \mathrm{~m} / \mathrm{s}$, the driver brakes hard for $2 \mathrm{~s}$, and the car decelerates at $10 \mathrm{~m} / \mathrm{s}^{2}$, after which the driver releases the brake and the car moves at $5 \mathrm{~m} / \mathrm{s}$ for additional $8 \mathrm{~s}$ without any braking. The brake disc parameters were modeled after an OEM no 43512-12550 rotor which is suitable for Toyota Corolla (liftback E11 and compact E11) cars.

The material parameters are outlined in Table 2.

\section{Results and Discussion}

Computational results of the modeling are presented in Figures 1, 2, 3, 4, 5, 6, 7, 8, 9, 10, 11, and 12 .

Figures 1 to 8 show the 3 dimensional temperature profiles for a car travelling at an initial velocity of $25 \mathrm{~m} / \mathrm{s}$ and then brakes for 2 seconds. It can be seen that the peak temperature occurs at 1.2 seconds. The highest temperature occurs at the contact surface of the disc-pads. The strong rise in temperature is due to the short duration of the braking phase and to the speed of the physical phenomenon. At the beginning of the braking action, the generated heat due to friction is very high and this frictional heat generated reduces gradually because the relative sliding velocity between the 


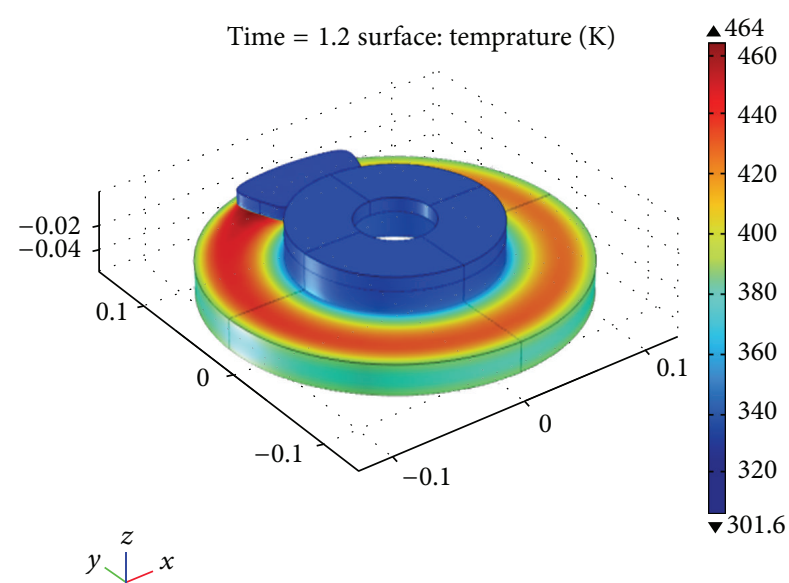

FIGURE 1: Temperature distribution for AMC disc and aramid pad at $t=1.2$ seconds.

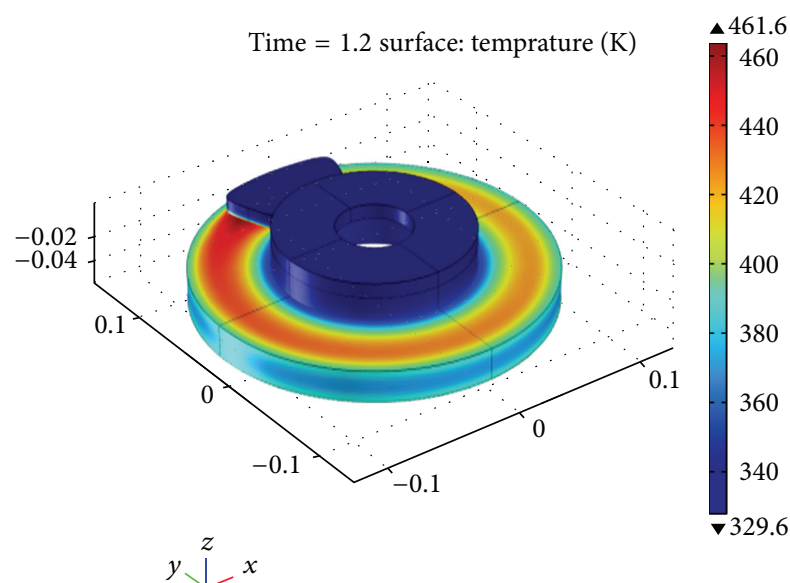

FIgURE 2: Temperature distribution for AMC disc and asbestos pad at $t=1.2$ seconds.

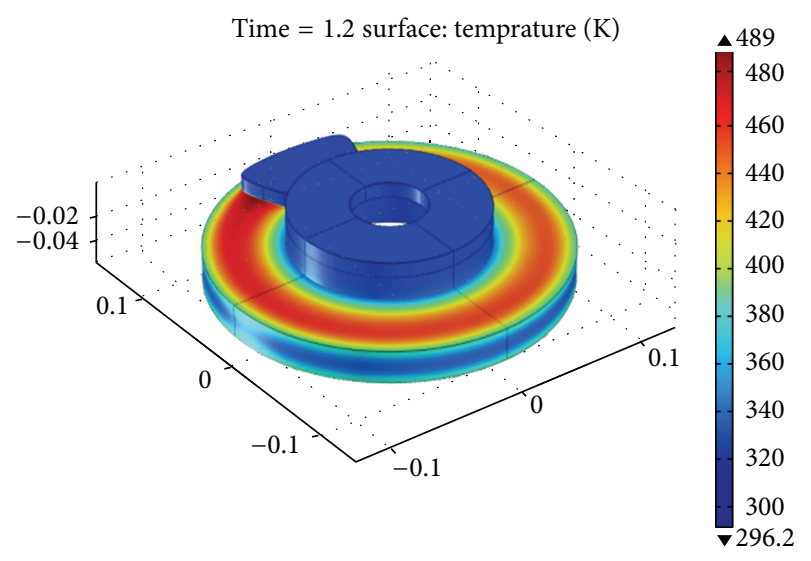

$$
y \stackrel{L}{z}^{x}
$$

FIgURe 3: Temperature distribution for GCI disc and aramid pad at $t=1.2$ seconds.

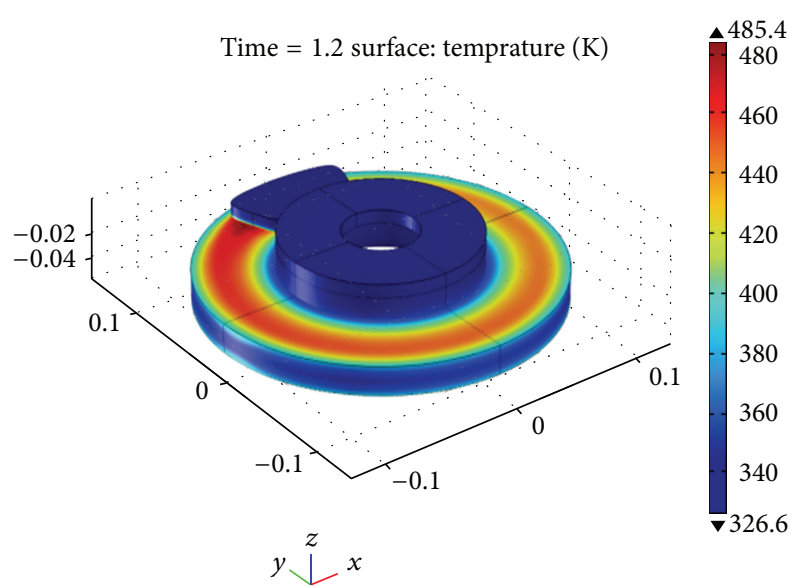

FIgURE 4: Temperature distribution for GCI disc and asbestos pad at $t=1.2$ seconds.

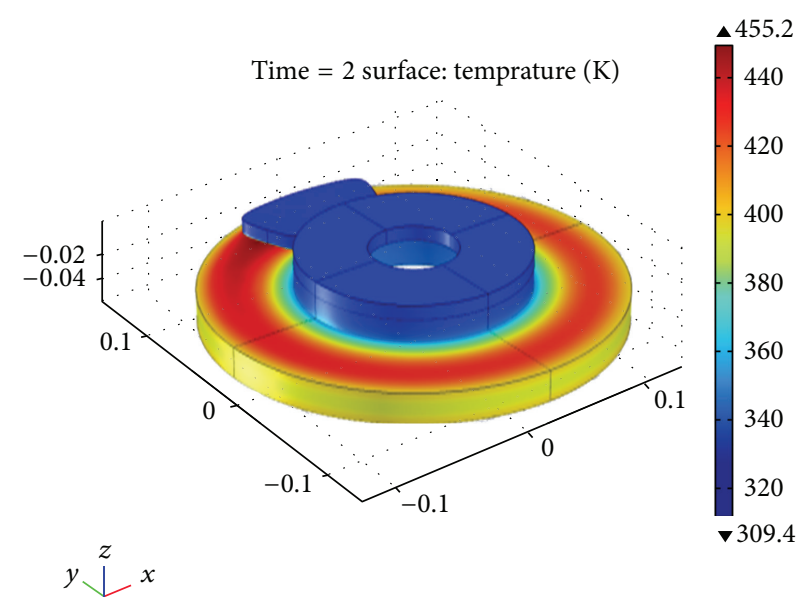

FIgURE 5: Temperature distribtion for AMC disc and aramid pad at $t=2$ seconds.

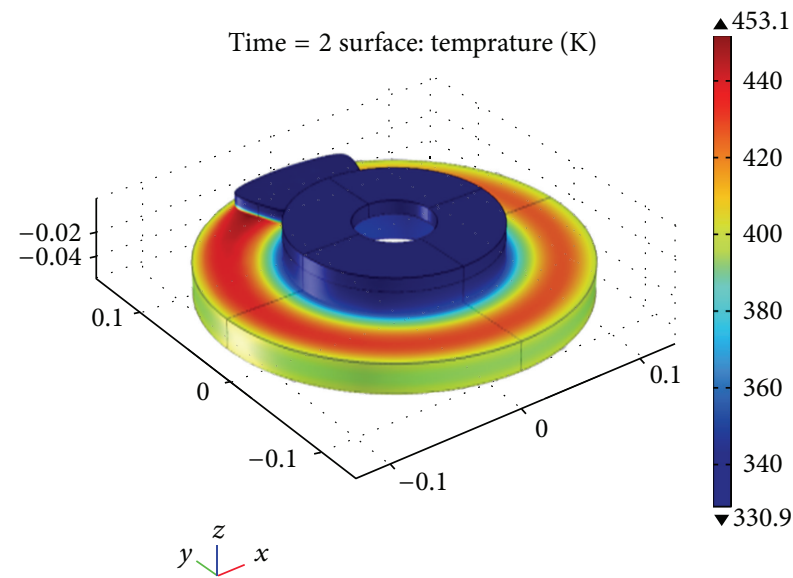

FIGURE 6: Temperature distribution for AMC disc and asbestos pad at $t=2$ seconds. 


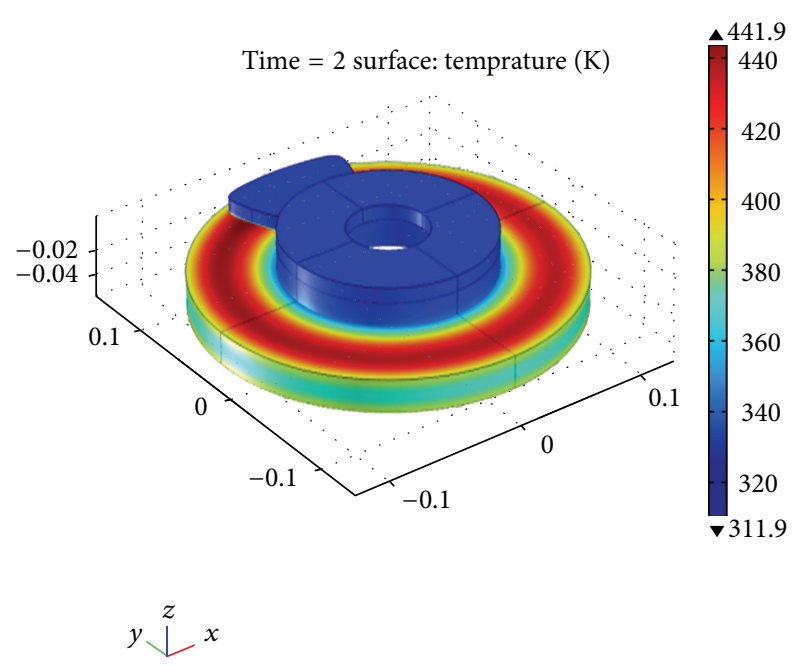

FIGURE 7: Temperature distribution for GCI disc and aramid pad at $t=2$ seconds.

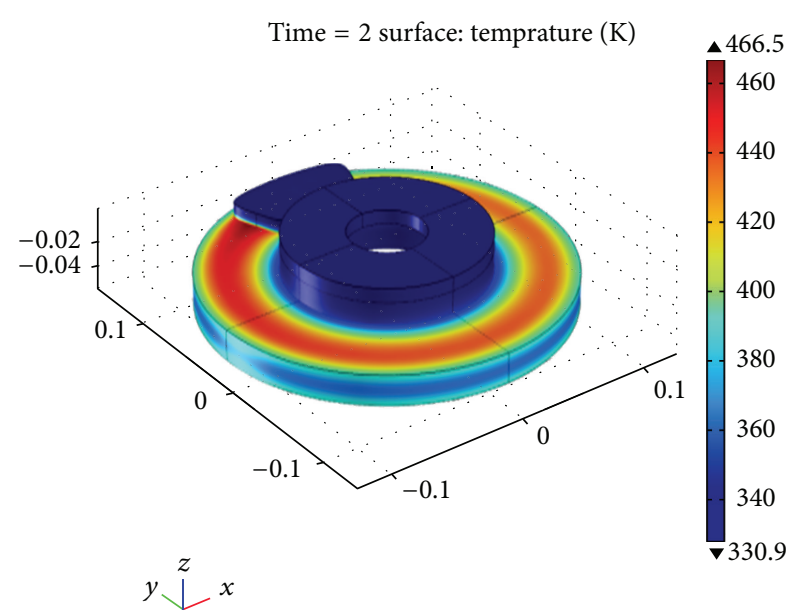

Figure 8: Temperature distribution for GCI disc and asbestos pad at $t=2$ seconds.

pad and the disk decreases with time during the braking action. Therefore at the end of the braking action $(t=$ 2 seconds), the heat generation is equal to zero. This is in good agreement with findings by Talati and Jalalifar model [3].

At $t=1.2$ seconds, the temperatures of the 4 models were as follows: AMC disc and aramid pad were $464 \mathrm{~K}$, AMC disc and asbestos pad were $461.6 \mathrm{~K}$, GCI disc and aramid pad were obtained as $489 \mathrm{~K}$, and GCI disc and asbestos pad were $485.4 \mathrm{~K}$. These temperatures occur at the centre of mass radius of the pad and disc contact surface $(r=0.1 \mathrm{~mm})$.

The combination of the GCI brake disc and aramid brake pad had the highest temperature (at $t=1.2$ seconds) of $489 \mathrm{~K}$ out of all 4 models. The modelling of temperature in the disc brake was carried out by taking account of the effect of the brake disc and brake pad materials.

3.1. Effect of the Disc Material. The plots in Figures 9 to 12 show the variation of temperature with time for the

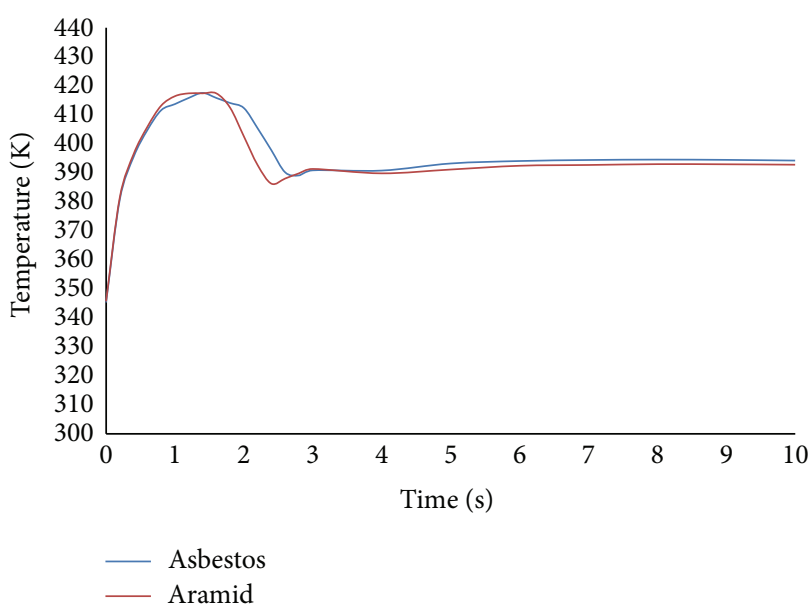

Figure 9: Temperature versus time plots for GCI brake disc and asbestos and aramid brake pads.

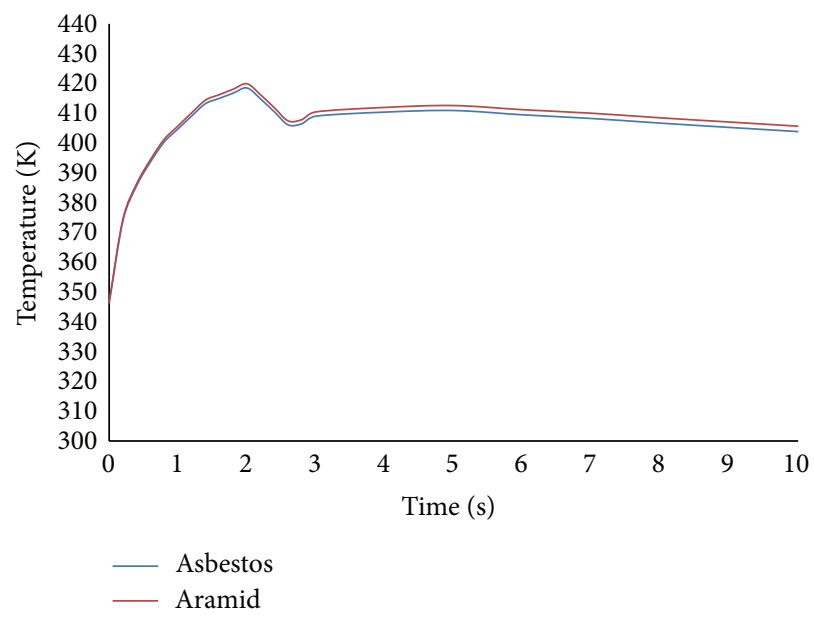

Figure 10: Temperature versus time Plots for AMC brake disc and asbestos and aramid Brake pads.

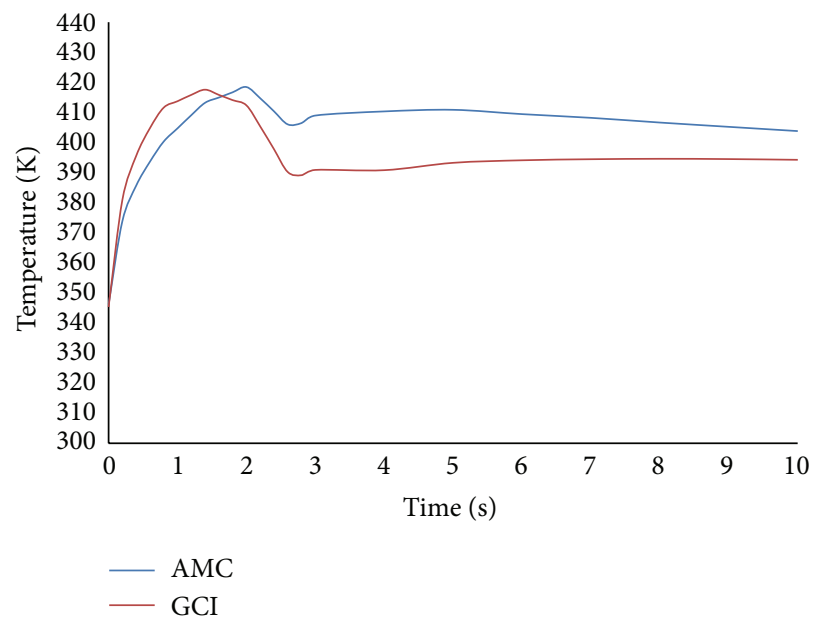

FIgURE 11: Temperature versus time plots asbestos brake pad and GCI and AMC brake discs. 
TABLE 1: Property table of brake disc and pad materials [4, 10-12] and COMSOL Multiphysics 4.0 software material library.

\begin{tabular}{lcccc}
\hline \multirow{2}{*}{ Properties } & \multicolumn{2}{c}{ Brake disc materials } & \multicolumn{2}{c}{ Brake pad (friction materials) } \\
& GCI & AMC & Asbestos & Nonasbestos organic aramid (Kevlar29) \\
\hline Thermal conductivity $(\mathrm{W} / \mathrm{mK})$ & 82 & 167 & 4 & 0.25 \\
Density $\left(\mathrm{kg} / \mathrm{m}^{3}\right)$ & 7200 & 2700 & 2500 & 1440 \\
Emissivity & 0.28 & 0.24 & 0.82 & 0.82 \\
Specific heat capacity $(\mathrm{J} / \mathrm{kgK})$ & 460 & 980 & 1060 & 1400 \\
Compressive strength $(\mathrm{MPa})$ & 1293 & 406 & & 70.5 \\
Friction coefficient & 0.41 & 0.35 & & 165 \\
Modulus of elasticity $(\mathrm{GPa})$ & & & & \\
\hline
\end{tabular}

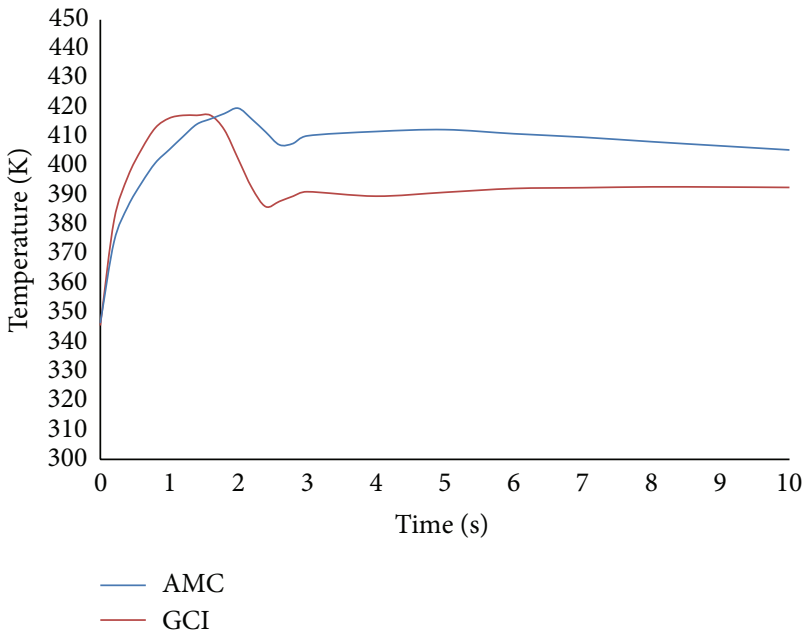

FIGURE 12: Temperature versus time plots aramid brake pad and GCI and AMC brake discs.

TABLE 2: Brake specifications and parameters.

\begin{tabular}{lc}
\hline Parameters & Value \\
\hline Outer disc diameter & $0.254 \mathrm{~m}$ \\
Disc thickness & $0.020 \mathrm{~m}$ \\
Disc hub inner diameter & $0.054 \mathrm{~m}$ \\
Disc hub outer diameter & $0.140 \mathrm{~m}$ \\
Pad thickness & $0.010 \mathrm{~m}$ \\
Pad area & $0.0032 \mathrm{~m}^{2}$ \\
Initial speed & $25 \mathrm{~m} / \mathrm{s}$ \\
Braking time & $2 \mathrm{~s}$ \\
Deceleration & $10 \mathrm{~m} / \mathrm{s}^{2}$ \\
\hline
\end{tabular}

different combinations of the brake discs and pads. Taking the asbestos brake pad as a datum material for the brake pad and comparing the AMC and GCI brake disc materials, as shown in Figure 9, we see that though the temperature reached (at $t=1.2$ seconds) is about the same at $485.4 \mathrm{~K}$, the GCI brake pad cools to a lower temperature (at $t=10$ seconds) and the AMC retains more heat for the release period after braking. This is also seen in the 3-D temperature profiles at 10 seconds (Figures 11 and 12) in which the AMC brake disc has a temperature of $404.3 \mathrm{~K}$ and the GCI is $394.7 \mathrm{~K}$. The temperatures obtained are quite close (with a difference of $9.6 \mathrm{~K})$.

3.2. Effect of the Brake Pad Material. Taking the GCI as the brake disc material and comparing the asbestos and aramid brake pad materials we see from the plot in Figure 10 that the thermal behavior of both materials is very close $T=489 \mathrm{~K}$ for aramid and $485.4 \mathrm{~K}$ for asbestos. This is similar to when the AMC is taken as the brake disc material (Figure 11). It is shown in the 3-D temperature profiles where at 10 secs (Figure 12) the difference in temperature between the asbestos and aramid is about $1.4 \mathrm{~K}$ and $1.8 \mathrm{~K}$ for the GCI and $\mathrm{AMC}$, respectively.

\section{Conclusions}

The following conclusions can be made from the results discussed above.

In the case of the brake pads, the alternative materialaramid, is suitable for the required function of a friction pad material. It showed similar traits to the common material in use, asbestos (which has hazardous health effects), and is thus an appropriate replacement for it as a friction material in brake pads. This conclusion agrees well with many recent researches on the product such as Satapathy and Bijwe [7], Wardle [8], and Patnaik et al. [9].

In the case of the aluminum metal matrix composite, the results also showed that it is a suitable alternative. Though the conventionally used grey cast irons are no danger to the health and are affordable, AMC has a lower density and higher thermal conductivity as compared to GCI and it results in weight reduction of up to $50-60 \%$ in brake systems [10] (see Table 1). Thus it can be applied in cases where less weight is specifically required for good performance, such as Formula-1 racing cars.

\section{Conflict of Interests}

The authors declare that there is no conflict of interests regarding the publication of this paper.

\section{References}

[1] P. J. Blau, Compositions, Functions, and Testing of Friction Brake Materials and Their Additives, Oak Ridge National Laboratory, Oak Ridge, Tenn, USA, 2001. 
[2] A. Belhocine and M. Bouchetara, "Thermal analysis of a solid brake disc," Applied Thermal Engineering, vol. 32, no. 1, pp. 5967, 2012.

[3] F. Talati and S. Jalalifar, "Analysis of heat conduction in a disk brake system," Heat and Mass Transfer, vol. 45, no. 8, pp. 10471059, 2009.

[4] M. Omolayo and J. Ogheneortega, Finite Element Analysis of Thermo Elastic Contact Problem of Disc Brake with Frictional Heat Generation, Prototype Engineering Development Institute (National Agency for Science and Engineering Infrastructure), Ilesa, Nigeria, 2011.

[5] W. Österle, H. Kloß, I. Urban, and A. I. Dmitriev, "Towards a better understanding of brake friction materials," Wear, vol. 263, no. 7-12, pp. 1189-1201, 2007.

[6] B. K. Satapathy and J. Bijwe, "Wear data analysis of friction materials to investigate the simultaneous influence of operating parameters and compositions," Wear, vol. 256, no. 7-8, pp. 797804, 2004.

[7] B. K. Satapathy and J. Bijwe, "Performance of friction materials based on variation in nature of organic fibres part I. Fade and recovery behaviour," Wear, vol. 257, no. 5-6, pp. 573-584, 2004.

[8] M. W. Wardle, Aramid fiber reinforced plastics- properties, E. I. DuPont de Nemours, Inc., Wilmington, Del, USA.

[9] A. Patnaik, M. Kumar, B. K. Satapathy, and B. S. Tomar, "Performance sensitivity of hybrid phenolic composites in friction braking: effect of ceramic and aramid fibre combination," Wear, vol. 269, no. 11-12, pp. 891-899, 2010.

[10] M. A. Maleque, S. Dyuti, and M. M. Rahman, "Material selection method in design of automotive brake disc," in Proceedings of World Congress on Engineering, 2010.

[11] P. J. Blau and H. M. Meyer III, "Characteristics of wear particles produced during friction tests of conventional and unconventional disc brake materials," Wear, vol. 255, no. 7-12, pp. 1261-1269, 2003.

[12] http://asm.matweb.com/search/SpecificMaterial.asp. 

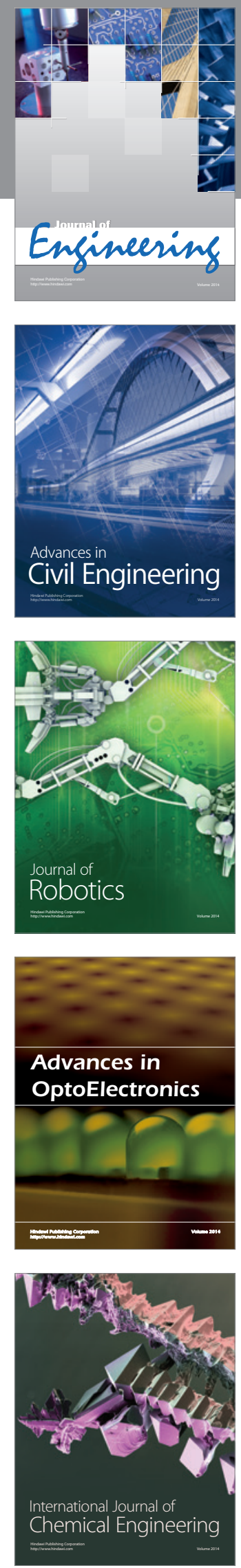

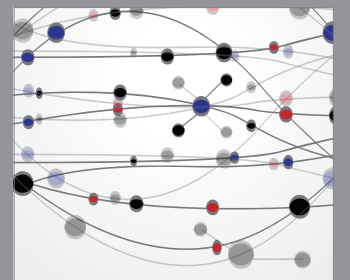

The Scientific World Journal
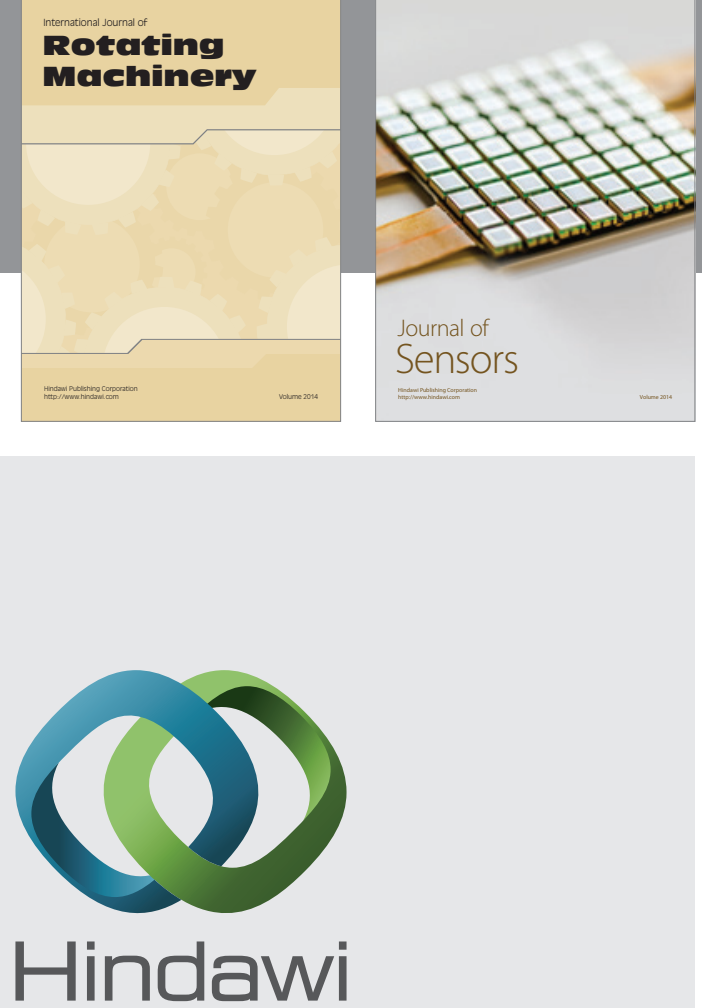

Submit your manuscripts at http://www.hindawi.com
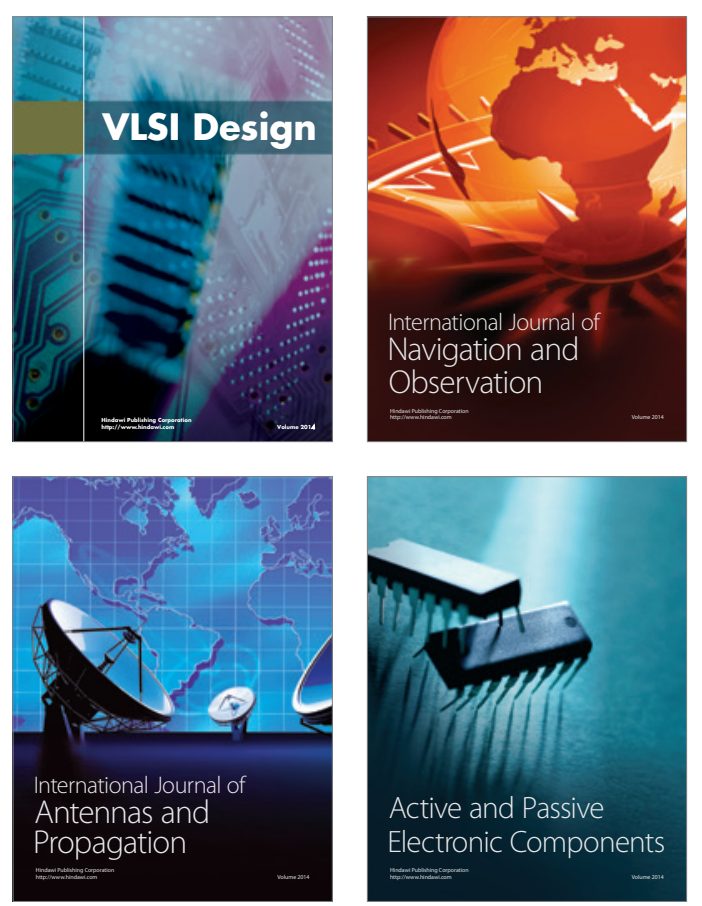
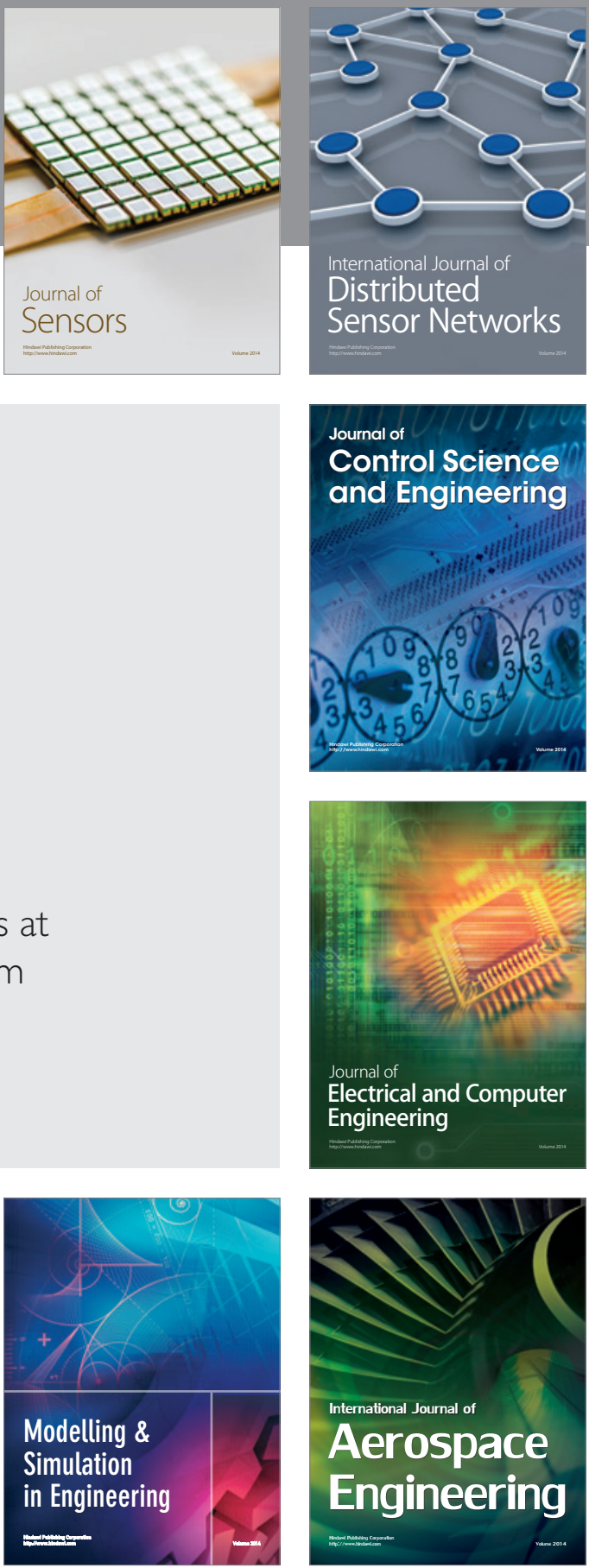

Journal of

Control Science

and Engineering
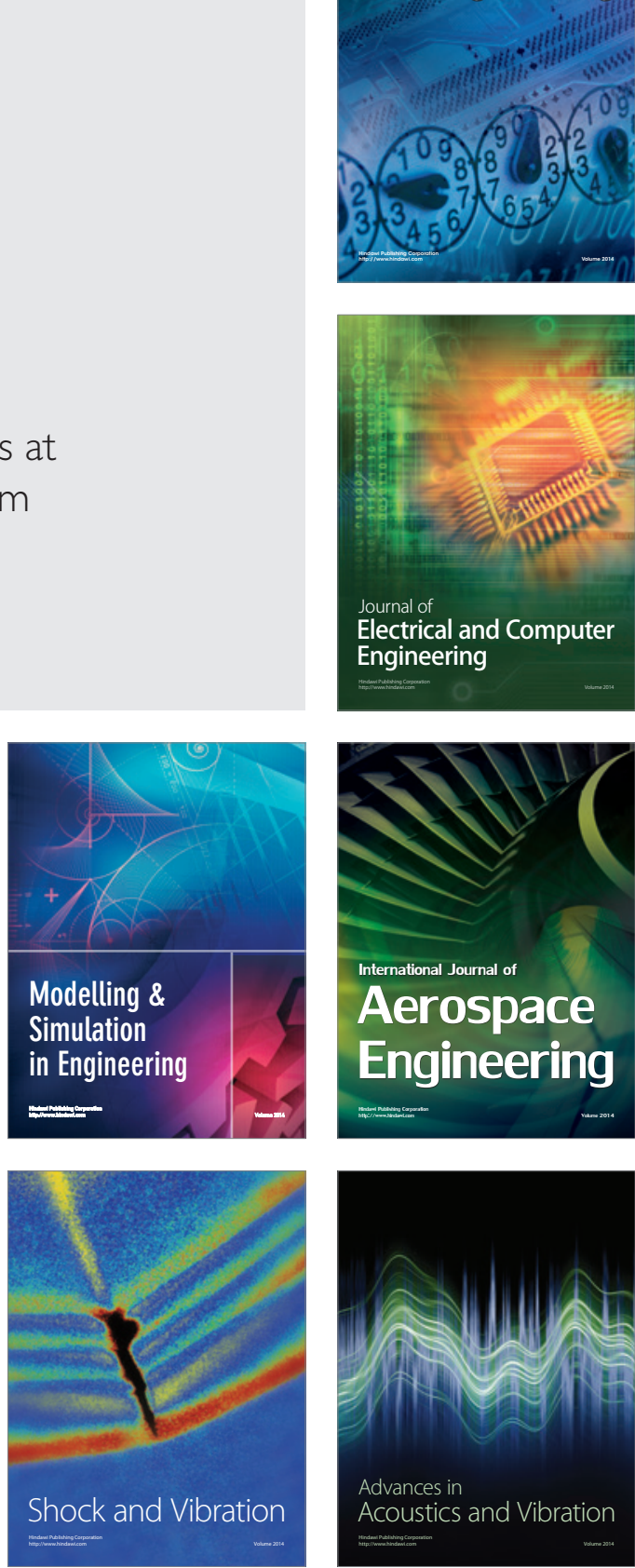